\title{
Influência das exigências legais e da teoria da administração na estrutura de tipos documentais em organizações ${ }^{1}$
}

Marcia Cristina de Carvalho Pazin Vitoriano

\begin{abstract}
Resumo
Introdução: Apresenta uma discussão sobre a criação e manutenção de modelos e fórmulas documentais ao longo do último século nas organizações privadas, sob os condicionantes da exigência legal e da Teoria da Administração. Método: Pesquisa de base documental, pautada na análise de três tipos documentais utilizados em organizações: diário geral, folha de pagamento e folder/folheto institucional. Resultados: São apresentadas e discutidas questões ligadas à regulação das atividades documentais por Lei, a influência da função administrativa de controle para analisar as permanências dos documentos, e as mudanças em tipos documentais mais comumente encontrados em arquivos privados. Conclusão: As estruturas presentes nos documentos de arquivo são influenciadas pelas exigências legais na medida em que, ao estabelecerem obrigações e fórmulas para estruturação da informação, produzem tipos documentais específicos, assim como os métodos e técnicas preconizadas pela Teoria da Administração refletem tanto na manutenção de tipos de documentos mais tradicionais quanto na criação de novas fórmulas.
\end{abstract}

\section{Palavras-chave}

Documentos arquivisticos. Gestão de documentos. Arquivos empresariais. Diplomática. Legislação arquivistica.

\section{Introdução}

Ao longo dos últimos séculos os estudos de Diplomática, entendida como a disciplina que tem por objeto a estrutura formal e a autenticidade dos documentos (CAMARGO, 2010), destinaram-se a compreender as estruturas documentais que possibilitavam aos documentos oficiais - em virtude de suas características - formalizar direitos e obrigações.

A necessidade de formalização dos atos em documentos está representada na própria origem do ato jurídico e a Diplomática define que é na concretização de um documento que se formaliza a possibilidade de produção de efeito do ato jurídico. Ou seja, a actio, enquanto ato de manifestação de vontade constitutivo do negócio jurídico, somente se concretiza na conscriptio, na escritu- ração, que é o ato de criação/formalização documental. Sobre este aspecto Duranti afirma que

a necessidade de uma forma escrita existe em duas circunstâncias: primeiro, quando o ato é de tal natureza que só pode chegar à existência por meio de um documento. $\mathrm{Ou}$, quando o ato que ocorre em forma oral, necessita de um documento como prova de sua existência. No primeiro caso o documento é o próprio ato, no segundo, o documento refere-se ao ato (1995, p. 54).

Porém, para além da área do Direito, o costume é outro mecanismo que parece ter tido significativa influência na manutenção das estruturas da documentação ao longo dos séculos. No Brasil, durante o período imperial, a elaboração dos documentos oficiais manteve as estruturas documentais trazidas pela Coroa Portuguesa desde o início da colonização, seguindo os mesmos modelos utilizados a partir da Idade Média (TAMA-

\footnotetext{
${ }^{1}$ Artigo elaborado a partir das discussões apresentadas na Tese de Doutorado "Obrigação, Controle e Memória: aspectos legais, técnicos e culturais da produção documental de organizações privadas", defendida pela autora no Departamento de História da FFLCH/USP em 2012.
} 
YO, 1996). Segundo o autor, uma prática comum nos órgãos oficiais da Península Ibérica era dispor de modelos completos de documentos que facilitassem a redação dos que se referiam a assuntos semelhantes. Dessa maneira, colecionando modelos diversos, nasceram os formulários diplomáticos (TAMAYO, 1996).

Essa característica, de "modelização" das fórmulas documentais persistiu durante o império brasileiro, em que muitos documentos seguiram (e seguem até hoje) as mesmas estruturas formais. Nas esferas administrativas brasileiras, há exemplos que prevalecem desde, pelo menos, o século XIX como, por exemplo, as folhas de pagamento, os diários gerais, os balanços e os orçamentos. De acordo com a pesquisa documental realizada para levantamento de dados para o presente trabalho, estes documentos apresentavam, já no período imperial brasileiro, uma estrutura muito semelhante à atual nas várias instâncias da administração (PAZIN VITORIANO, 2005).

A evolução da Teoria da Administração ao longo do último século, assim como a ampliação da abrangência das relações de negócio e da atuação das organizações em diversos segmentos sociais, exigiu que o aparato administrativo acompanhasse as novas demandas da sociedade. A busca por eficiência (base do desenvolvimento das organizações), o aparecimento de um arcabouço tecnológico voltado à gestão empresarial, e as novas relações de trabalho que se estabeleceram nas últimas décadas, modificaram significativamente o processo de gestão administrativa e, consequentemente, influenciaram toda a produção documental das organizações.

Adicionalmente, exigências legais tendem a padronizar e regular a produção e os tipos documentais, inclusive em um processo de "formularização", que visa ao estabelecimento de padrões facilmente reconhecíveis e que contribuem para a confiabilidade e a garantia de autenticidade. Nesse contexto, a formularização pode ser entendida como o estabelecimento de formulários documentais - modelos de espécies ou tipos documentais, contendo espaços para o registro de dados variáveis (CAMARGO, 2010, p. 50). Ape- sar de essa tendência ser um aspecto ligado à regulamentação legal das atividades, ela apresenta também um aspecto técnico, pois a padronização - como forma de reconhecimento da validade do documento - prevalece mesmo onde não é obrigatória. Por exemplo, ao longo do século $\mathrm{XX}$, a informatização mudou consideravelmente o processo de registro das informações e a emissão de documentos. Porém, é interessante notar que, mesmo em meio eletrônico, alguns formulários permanecem similares aos documentos tradicionais, o que leva, por exemplo, ao seguinte questionamento: por que os novos documentos oficiais, tais como os guias de recolhimento de impostos, gerados em meio eletrônico, resultam em documentos comprobatórios com as mesmas características formais que os documentos manuscritos ou datilografados durante décadas?

Esta aparente contradição é enfrentada no presente texto que tem como objetivo discutir a influência das exigências legais e dos diversos modelos teóricos aplicados ao estabelecimento de padrões na tipologia documental em organizações privadas contemporâneas.

\section{Referencial teórico}

No ambiente de produção documental convencional, a criação de fórmulas tem como objetivo facilitar o reconhecimento e a legalidade e autenticidade de um documento. Porém, no ambiente digital, a autenticidade está presente na codificação binária do processamento eletrônico voltada à geração de um código numérico de confirmação. Não é, portanto, o formulário que atribui essa facilidade de reconhecimento, o que torna a manutenção destes no ambiente digital um instrumento de padronização mais ligado ao reconhecimento do documento como tal, do que a uma obrigatoriedade formal exigida.

A padronização parece ocorrer de maneira similar em diversas atividades, até chegar, quando necessário, ao ponto em que a regulamentação legal assume como fórmulas adequadas e oficiais aquelas que são aplicadas rotineiramente. Nos exemplos tratados no presente trabalho encontram-se 
situações representativas como, por exemplo, o fato da técnica contábil ser muito mais antiga do que a legislação comercial, esta do século XIX. Ao formular o Código Comercial Brasileiro, em 1850, o legislador definiu a obrigatoriedade de escrituração de alguns documentos já tradicionalmente preconizados pela técnica contábil tradicional (MILANI, 2004, p. 145-146).

A atuação da sociedade influencia a criação e consolidação de controles legais em temas considerados importantes. Esses temas geram processos que se cristalizam ao longo do tempo, gerando fórmulas documentais estáveis. No caso da administração de organizações, esse processo também ocorre, e parece haver uma oposição entre tipos documentais que ganham estabilidade ao longo dos anos e outros, tidos como instáveis, que são representativos de processos ainda não consolidados, ou que estão fortemente influenciados por mecanismos sociais em constante mudança.

Atividades essenciais nas organizações tendem a gerar documentos mais estáveis do que atividades administrativas acessórias, seja por questões legais ou técnicas. Não por coincidência, muitas vezes, as atividades essenciais são também, aquelas reguladas, justamente porque nessas atividades deve estar presente a formalização legal necessária para consecução dos objetivos e produção do efeito necessário.

Mesmo considerando que a produção documental é mais estável do que as mudanças provocadas pelas diversos modelos administrativos aplicados, deve-se ressaltar que, ao longo da primeira parte do século XX, a produção documental das organizações foi fortemente influenciada pela teoria da burocracia de Max Weber (MOTTA, 1986, p. 80) e pelo método de departamentalização funcional (MAXIMIANO, 2004, p. 229), na medida em que a criação de uma estrutura administrativa pressupõe a estabilidade dos processos, a qual é representada pela igual estabilidade dos tipos documentais existentes. Por outro lado, a instabilidade documental revela-se no desenvolvimento de novos processos e na complexidade administrativa formulada pela Teoria dos Sistemas, desenvolvida a partir dos anos 1970, como parte das grandes mudanças organizacionais produzidas pela ampliação do uso da Tecnologia da Informação (TI) nos processos administrativos (CHIAVENATO, 2000). O desdobramento desta teoria alterou significativamente o "modo de fazer" administrativo, influenciando principalmente aquelas atividades em que a técnica prevalece sobre a exigência legal.

Um exemplo clássico é o uso de sistemas como o Enterprise Resource Planning (ERP) como mecanismo de gerenciamento de processos. Esses sistemas foram criados para dar suporte e coordenar os processos e áreas funcionais de qualquer organização, valendo-se de uma base de dados única, na qual todas as transações estivessem registradas. Composto por módulos integrados, estes podem atender a cada área funcional ou processo e coordenar suas ações. Em algumas áreas, tais como Produção e Logística, o uso de ERP transferiu para o meio eletrônico processos já consolidados, gerando documentos similares aos que eram produzidos em meio convencional (SOUZA, 2003, p. 325).

Naquilo que é considerado essencial como, por exemplo, a documentação contábil, os documentos de relações de trabalho e os documentos jurídicos, a influência tecnologia ocorreu mais fortemente na década de 1980, com a transposição de processos já padronizados anteriormente. Porém, tal condição não mudou a estrutura documental em si, influindo apenas na forma de processar tais documentos, conforme afirma Souza em seu estudo de processos para implantação de sistemas ERP (2003, p. 47). Ao se considerar outras atividades com menor influência da legislação - ou de determinada Teoria da Administração -, como o caso dos processos de trabalho, percebeu-se uma volatilidade na produção documental a qual responde às necessidades ou interesses do momento, gerando documentos sazonais ou efêmeros. Os relatórios gerenciais são um exemplo importante dessa situação. A interpretação das necessidades de informação administrativa é influenciada pela vivência pessoal do administrador em seu processo de trabalho e, em geral, ao definir quais informações são necessárias naquele mo- 
mento, cabe a ele criar ou eliminar documentos de controle.

Esse, todavia, não é um problema novo. Desde o início do século XX, os primeiros teóricos da Administração preocupavam-se com essas questões. A Administração Científica preconizava a padronização dos procedimentos e, consequentemente, dos tipos documentais produzidos na realização das funções e atividades. Isso ocorria principalmente pela percepção de que a existência de padrões (tantos procedimentais quanto documentais) levaria ao aumento da eficiência produtiva. Esse conceito aparece tanto nos escritos de Taylor (1966), pai da Administração Científica, quanto em seus seguidores.

Harrington Emerson, engenheiro de ferrovias e responsável pela popularização das ideias de Taylor, defendia a existência de um sistema padronizado de registros de produção nas nascentes fábricas modernas, como mecanismo de eficiência administrativa (LODI, 1981, p.35). Para Emerson, a produção documental era um problema de Administração pois

\footnotetext{
Não é incomum encontrar nos registros de uma organização grande variedade de tabulações mensais, e quando se investiga por que elas existem, vem à luz que, vinte anos antes, algum presidente quis um certo tipo de registro, e que seu sucessor quis um outro que passou a ser feito em paralelo, e que um terceiro e quarto presidentes agregaram outras exigências, mas as velhas tabulações continuaram a ser feitas; e dedicados funcionários trabalharam ao longo de suas vidas monótonas para uma clara compilação à qual ninguém olhou nem usou por uma década (EMERSON apud LODI, 1981, p. 35).
}

Assim como Taylor, Henri Fayol (1970) também estava preocupado com o registro das operações e o controle da administração. Ao definir as funções administrativas, Fayol apresenta a função de Controle como especialmente importante para a produção documental, pois esta se refere à capacidade de verificação das demais funções cumpridas pela organização (FAYOL, 1970, p. 25). Segundo ele, as operações de controle são aplicáveis a quaisquer funções administrativas uma vez que se trata de saber: se o programa definido existe; se está sendo realizado (e se obedece aos princípios adotados); onde estão alocadas as matérias-primas; e, onde estão os estoques de produtos acabados. Tecnicamente, envolve o controle de produção, da qualidade, do funcionamento de máquinas e dos trabalhadores e, financeiramente, se situa no controle do fluxo financeiro e de sua aplicação. No âmbito da contabilidade, que é uma função de registro por excelência,

é preciso verificar se os documentos necessários chegam rapidamente, se eles proporcionam visão clara da situação da empresa, se o controle encontra nos livros, nas estatísticas e nos diagramas bons elementos de verificação e se não existe nenhum documento ou estatística inútil” (FAYOL, 1970, p. 25).

A função de controle implica, obrigatoriamente, produção de documentos, os quais têm como objetivo registrar a efetiva realização das funções administrativas. Para os arquivistas, a questão está em compreender quais desses tipos documentais se consolidarão em fórmulas perenes. Somente fórmulas consolidadas sobrevivem e tendem a se tornar hegemônicas para determinadas atividades, produzindo documentos recorrentes ao longo do tempo. A consolidação de determinados tipos documentais, resultado do processo de modelização tratado no início desse trabalho, é um dos mecanismos que possibilitam o reconhecimento da confiabilidade e da autenticidade dos documentos de arquivo (PAZIN VITORIANO, 2012).

\section{Análise de tipos documentais em organizações: arcabouço legal e questões conceituais}

Considerando as questões apresentadas anteriormente, pode-se dizer que a consolidação das fórmulas depende da combinação de exigências legais e métodos administrativos, que em conjunto propiciam a criação de estruturas documentais que prevalecem ao longo do tempo.

Para ilustrar essa situação, são apresentados alguns exemplos de tipos documentais considerados estáveis e normalmente encontrados nas administrações públicas ou privadas. 


\section{Documento 01: diário geral}

Uma das atividades técnicas mais antigas de que se tem notícia nas relações comerciais, a Contabilidade, é definida como a aquela de classificação e registro das transações de uma organização, que possam ser expressas em termos monetários, de acordo com um planejamento definido e sintetizado em um plano de contas, especialmente o registro e a análise dos valores pagos, recebidos, devidos e a receber. Seu objetivo é fornecer informações exatas sobre a situação econômica e financeira da organização aos administradores e dirigentes (LACOMBE, 2009, p. 151).

A exatidão preconizada pela técnica fez com que a escrituração contábil estivesse presente no Direito Comercial desde as suas origens e, conforme relata Milani

[s]e nenhuma lei impunha, de modo absoluto, aos mercadores a obrigação de ter livros, todavia, a existência deles entrava no rol dos bons usos e costumes. Todos os estatutos continham numerosas disposições sobre os livros mercantis e alguns deles até mesmo regras precisas sobre contabilidade. Os livros deviam ser selados e rubricados pela autoridade judiciária, com a indicação das folhas que continham, e apresentar na primeira folha o nome de seu proprietário e do preposto encarregado de escriturá-lo. Todas essas cautelas visavam, certamente a assegurar a eficácia probatória dos livros mercantis (2004, p. 146).

Somente com a evolução do Direito Comercial, a obrigação da escrituração contábil passou a ser regulada por Lei. No Brasil, durante todo o período Colonial não havia obrigação legal de adoção de livros para o exercício da profissão de mercador. Apenas alguns alvarás específicos definiam a obrigação de apresentar livros de registro diário, em caso de falência. Com o Código Comercial de 1850, o Brasil instituiu a obrigatoriedade de "seguir uma ordem uniforme de contabilidade e escrituração e de ter livros para esse fim necessário" (BRASIL, 1850).

Esse é o caso do diário geral. Trata-se de um livro de escrituração contábil, de uso obrigatório, em que se registram em ordem cronológica todas as operações de débito e crédito dos fatos econômicos constitutivos da atividade das organizações, bem como o resumo do balanço. Um dos principais documentos de escrituração contábil até os dias atuais, o (livro) diário geral é considerado documento obrigatório desde a criação do Código Comercial (BRASIL, 1850).

A escrituração contábil é uma atividade altamente regulamentada pela legislação devido às implicações tributárias envolvidas nos registros financeiros das organizações. No Brasil, atualmente, a escrituração contábil é regida pelo Código Civil (Lei 10406/2002), que revogou o antigo Código Comercial, em vigor desde 1850. Nele, está definido que as organizações são obrigadas a seguir um sistema de contabilidade baseado na uniformidade de seus livros, que correspondam à documentação de lançamento das ocorrências e a levantar anualmente o balanço patrimonial e o resultado econômico, utilizando-se para isso as demonstrações financeiras. O livro diário geral também é obrigatório, seja ele elaborado por meios convencionais ou eletronicamente, e deverá ser autenticado nos registros públicos respectivos, com a inclusão do balanço patrimonial e da demonstração dos resultados no corpo do livro. Esse processo de registro é denominado escrituração contábil (BRASIL, 2002).

O diário geral deve ser encadernado e registrado na Junta Comercial e conter um termo de abertura e, quando terminado, um termo de encerramento. Não pode conter rasuras, emendas ou linhas em branco (LACOMBE, 2009, p. 217).

No seu artigo 1.191, o Código Civil determina a obrigatoriedade de apresentação do diário geral para "resolver questões relativas à sucessão, comunhão ou sociedade, administração ou gestão à conta de outrem, ou em caso de falência”. Como não há prazo de prescrição para essa operação, entende-se que a exibição poderá ser solicitada a qualquer tempo, por isso o prazo de guarda do diário é sempre permanente.

Porém, toda a exigência legal apresentada anteriormente foi originada partir da existência prévia de uma técnica administrativa de escritura- 
ção, originalmente sem relação com a exigência legal.

Retomando Luciana Duranti, assim como a origem do fato jurídico se dá na formalização escrita - onde os atos efetivamente se concretizam - o ato administrativo, considerado como a formalização das transações resultantes da gestão de qualquer organização, deve ser registrado para produzir efeito (DURANTI, 1995, p. 54). Assim, uma prática secular, de característica essencialmente técnica tornou-se o modelo utilizado pelo legislador no momento de fixar os fatos jurídicos do Direito Comercial.

Porém, por seu caráter generalista, a estrutura do documento mudou pouco ao longo de vários séculos, tendo sido a maior mudança a transposição dos livros de escrituração para os relatórios gerados eletronicamente e encadernados a posteriori. $\mathrm{O}$ formato de tabela, o registro dos lançamentos (entradas e saídas) manteve-se praticamente inalterado ao longo do tempo. Nes-se caso a tecnologia da informação influenciou a capacidade operativa, mas não a estrutura documental.

\section{Documento 02: a folha de pagamento}

A folha de pagamento é outro documento que pode ser analisado da mesma forma, considerando tanto a questão legal, como a influência das técnicas administrativas Ela é um dos documentos representantes, por excelência, do controle nas relações de emprego.

Folha de pagamento é um relatório geral mensal, elaborado pelo empregador, que contêm as informações de valores de remuneração, descontos e abatimentos, acréscimos e o valor líquido pago aos funcionários (LACOMBE, 2005, p. 294). Quando destinada ao serviço público, também costumava ser denominada como folha de vencimentos, como ocorre especialmente em documentos do século XIX (PAZIN VITORIANO, 2005),
O artigo 225 do Regulamento da Previdência Social (BRASIL, 1999) regula a emissão da folha de pagamento. Ali está dito que o empregador deve

"preparar folha de pagamento da remuneração paga, devida ou creditada a todos os segurados a seu serviço, devendo manter, em cada estabelecimento, uma via da respectiva folha e recibos de pagamentos".

Apesar de existir a determinação do registro, a Lei não esclarece como esse documento deve ser estruturado. Aqui, a função administrativa representada no documento fornecerá a estrutura mínima necessária para sua composição.

Considerando que a relação de emprego baseiase numa troca, na qual os funcionários cedem ao empregador seu tempo e trabalho, e o empregador cede aos funcionários a remuneração pelo trabalho realizado, o controle do cumprimento dos compromissos por ambas as partes é uma das principais preocupações de empregadores e empregados. Duas operações resumem esse processo: o controle de frequência e a elaboração da folha de pagamento.

A folha de pagamento é elaborada a partir das informações registradas nos documentos de controle de frequência, especialmente livro ou folha de presença, cartões de ponto (sistema mecanizado com uso de relógio) ou nos relatórios gerados por terminal eletrônico. A partir dos dados apontados no registro de frequência, inicia-se a elaboração da folha, que envolve o cál-culo da diferença entre o salário base a ser considerado (registrado em carteira), deduzido dos impostos e encargos a serem descontados do trabalhador, além das eventuais faltas e venci-mentos extras a serem recebidos pelo funcionário. $\mathrm{O}$ resultado desse cálculo representa o rendimento líquido do trabalhador. Além do cálculo de salário, a folha de pagamento é o instru-mento geral de cálculo de todos os encargos sociais e tributos a serem recolhidos pela organi-zação, relativos aos empregados.

Assim como o diário geral, a folha de pagamento é um documento anterior à legislação traba-lhista e, desde seus primórdios tinha como objetivo o 
registro e controle dos valores pagos aos funcionários, considerando a relação contratual que se estabelecia.

O advento da legislação trabalhista consolidou o documento como memória de cálculo de salários, encargos e tributos, o que garantiu a fixação de alguns padrões em sua estrutura.

Até a primeira metade do século XX encontrase, assim como para os documentos contábeis, dos quais o diário geral, tratado anteriormente, é um dos exemplos, as folhas registradas em formato de tabela, em livros ou folhas avulsas, em que cada linha é representada pelos dados de um funcionário e cada coluna um valor específico a ser pago ou descontado.

Diferentemente do que ocorreu com o diário geral e demais relatórios contábeis, o advento da informática modificou a estrutura da folha de pagamento. A tecnologia possibilitou uma reorganização dos processos de trabalho de tal ordem que atividades registradas antes em diver-sos documentos tiveram seu registro consolidados em um documento único, fornecendo a estrutura da folha de pagamento, tal qual conhecemos hoje. Nesse caso, percebe-se que onde não há obrigatoriedade de fórmulas documentais, mas o registro das atividades é necessário, a estrutura documental se simplifica. No caso da folha de pagamento, a estrutura tradicional de tabela foi modificada. A partir da década de 1980, a popularização dos pacotes de softwares de gestão administrativa e financeira trouxe novos formatos, fixando uma fórmula em que o registro dos dados de cada funcionários ficava condensado num bloco de informações. Cada item repete as informações, que são individualizadas por funcionário. Embora as informações se mantenham, a apresentação foi modificada. A partir de então, esse modelo tornou-se praticamente o único encontrado nos documentos contábeis desta natureza.

Além das questões de estrutura, outra importante análise está relacionada à terminologia utilizada. Durante a pesquisa documental, identificou-se que o termo folha é uma tradução do inglês sheet, tradicionalmente utilizado para identificar, entre outros documentos, aquele resultante da memória de cálculo (memory sheet), muitas vezes em formato de tabela, encontrado em arquivos de empresas de matriz americana. Conforme relata Alfred Chandler, a gradual profissionalização da atividade de gestão administrativa no início do século XX possibilitou a difusão e consolidação de métodos e técnicas já utilizados desde o século XIX, o que parece ter contribuído para o estabelecimento de fórmulas documentais, que chegaram ao Brasil por meio de profissionais vindos do exterior para trabalhar em empresas multinacionais e das escolas de Administração (CHANDLER, 1988, p. 628).

Essa nomenclatura sobreviveu ao longo de mais de cem anos, e ainda permanece usual. Embora o termo relatório de pagamento pudesse ser usado para definir o tipo documental, não re-presentaria efetivamente o documento, uma vez que o termo relatório de pagamento é tradicionalmente utilizado para identificar o documento que registra a efetivação dos pagamentos realizados - um documento financeiro, portanto. A terminologia "folha" consolidou a existência de uma memória de cálculo subjacente ao documento.

\section{Documento 03: o folder}

Outro tipo de documento - ou de um formato, mais precisamente utilizado na área de Comunicação se apresenta como emblemático em relação aos problemas terminológicos da tipologia documental moderna. Trata-se do folder - ou tecnicamente mais corretamente denominado prospecto ou folheto. Esse caso é emblemático ao se considerar o problema dos formatos nas estruturas documentais mais modernas, representando um descompasso entre a teoria arquivística e a prática administrativa. Algumas definições podem auxiliar na reflexão do caso:

a) folder é um formato constituído de uma única folha impressa contendo uma ou mais dobras, que apresenta conteúdo informativo ou publicitário (MOREIRA, PASQUALE, DUBNER, 2008, p. 210); 
b) prospecto é um documento caracterizado por ser uma folha de papel impressa com propaganda ou divulgação de alguma ideia, evento, produto, serviço, empresa (HOUAISS, 2013) (é considerado similar ao folder, porém muito mais simples em termos de sua produção);

c) folheto é um formato de publicação não periódica, com número limitado de páginas, no mínimo de cinco e máximo de 48, excluídas as capas (RABAÇA; BARBOSA, 1995, p. 274).

Trata-se de formatos consolidados que, embora com diferenças técnicas, são utilizados para finalidades semelhantes. $O$ folder é um tipo específico de folheto caracterizado pela folha única, dobrada. Pode ser utilizado para diversas finalidades de divulgação, dependendo do objetivo de comunicação. O tipo documental é definido por sua função. Há o folder institucional, o folder de divulgação de evento, entre outros. Diferentemente do folder, o folheto é usualmente encadernado em brochura ou canoa (grampeado). A possibilidade de agregar um maior número de páginas tem reservado a utilização do termo folheto para designar documentos com acabamento gráfico mais elaborado, e com maior volume de informação.

Esse é um tema importante no trabalho do arquivista e,

\begin{abstract}
como os tipos documentais não são estáticos, e podem sofrer mudanças de forma e de fundo, o que faz com que a nomenclatura também tenha se alterado ao longo dos séculos, é imprescindível que o trabalho de análise esteja submetido às normas e princípios mais comumente aceitos atualmente, de modo que todos os membros do grupo empreguem uma mesma nomenclatura em seus trabalhos (CORTÉS ALONSO, 1986, p. 420).
\end{abstract}

É importante que a nomenclatura utilizada seja adequada àquela organização e correta do pon-to de vista de suas características técnicas. Por isso se deve considerar também a evolução da língua e a influência dos termos técnicos como fatores que influenciam a atribuição da nomenclatura aos tipos documentais. Contudo, ao atribuir títulos aos tipos documentais analisa-dos, não se desconsidera a influência das técnicas de admi- nistração na gestão das organizações, assim como a dos documentos públicos similares.

O folder é um exemplo representativo dessa situação nos arquivos de comunicação e marketing das mais diversas organizações. A rigor, trata-se de um prospecto dobrável ou de um fo-lheto, composto de apenas uma folha dobrada. Porém, desde a década de 1980, os teóricos da Comunicação no Brasil, influenciados pela teoria norte-americana (RABAÇA, BARBOSA, 1995, p. 272), utilizam esta expressão para designar o documento "folder", ao ponto de que em muitas ocasiões, ao se solicitar os 'prospectos' da organização para análise, provavelmente se obterá a resposta de que a organização não produz este tipo de documento. Ocorre que, ao longo do tempo, e com o uso frequente, gradativamente os nomes foram se consolidando e criando uma diferença concreta entre si. A partir do uso constante, folder, folheto e prospecto se diferenciaram. Atualmente, a designação comum utilizada para os folhetos dobrados sem grampos, é folder, conforme Moreira, Pasquale e Dubner $(2008,2010)$. O folheto passou a ser destinado a conteúdos mais elaborados e, com isso, o termo prospecto vai gradativamente caindo em desuso. Quando utilizado, define apenas pequenos folhetos de folha única, em duas páginas, sem dobras, bem próximo do que é um volante ou filipeta, sem tratamento gráfico mais apurado, utilizado em situações corriqueiras ou pouco profissionais.

\section{Considerações finais}

Deve-se considerar que a utilização de determinados termos também será influenciada pelo conhecimento técnico e pela terminologia utilizada nas diversas áreas do conhecimento. Entende-se que, preferencialmente, o termo utilizado deve ser representativo de seu significado para aqueles que o produzem e utilizam, e não uma imposição técnica de uma área externa à produção documental.

Os três exemplos apresentados demonstram como a legislação e as técnicas administrativas regulam as atividades, e quais tipos documentais 
tendem a se manter mais estáveis, mesmo com a evolução tecnológica.

Como se demonstrou no decorrer da análise, a permanência ou a mudança na estrutura dos tipos documentais das organizações privadas está intimamente relacionada à necessidade do administrador, seja para o cumprimento de uma obrigação legal, seja para a eficiência administrativa.

Se por um lado, a legislação fortalece preservação de tipos documentais estáveis, uma vez que o cumprimento da obrigação legal pressupõe a definição externa de procedimentos e sua estabilidade; por outro, na ausência de uma regulação estrita dos tipos documentais, ou para os quais as Teorias da Administração preconizem mudanças e atualizações de acordo com as necessidades de mercado, a estrutura documental tenderá a ser alterada de acordo com as necessidades administrativas. Ao se transformarem as organizações, o mesmo acontecerá com seus documentos. A questão é compreender em que momento essa mudança é de tal ordem que o próprio trabalho de análise do arquivista deverá ser atualizado. Os instrumentos de gestão de documentos - especialmente o plano de classificação - são fortemente influenciados por essas mudanças. Cabe ao arquivista avaliar se a modificação sofrida no tipo documental é resultante de uma alteração na função desempenhada ou apenas da alteração da estrutura física do documento, mantendo-se a função essencial.

Analisar a tipologia documental de uma organização, identificando os tipos específicos de documentos encontrados, e compreender seu histórico de criação e manutenção, é uma das ferramentas para a efetiva identificação documental, o que virá a facilitar a criação de instrumentos de gestão mais adequados à sua produção.

\section{Referências}

BRASIL. Decreto 3.048, de 06 de maio de 1999. Aprova o Regulamento da Previdência Social, e dá outras providências. Diário Oficial da União, 21 jun. 1999. Disponível em: <http://www.planalto.gov.br/ccivil_03/ decreto/D3048.htm> Acesso em: 1. dez. 2013.

BRASIL. Lei 556, de 25 de junho de 1850. Código Comercial. CLB de 185 T.11, p. 57-238. Disponível em <http://www.planalto.gov.br/ccivil_03/leis/L05561850.htm> Acesso em: 1. dez. 2013.

BRASIL. Lei 10.406, de 10 de janeiro de 2002. Institui o Código Civil. Diário Oficial da União, 11 jan. 2002. Disponível em: <http://www.planalto.gov.br/ccivil_03/ leis/2002/L10406.htm> Acesso em: 1. dez. 2013.

CAMARgO, A. M. A; BELlOTTO, H. L. Dicionário de terminologia arquivística. São Paulo: Centro de Memória da Educação FEUSP/FAPESP, 2010.

CHANDLER, A. D. Mano visible: la revolución en la dirección de la empresa norteamericana. Madrid: Ministerio del Trabajo e Seguridad Social, 1988.

CHIAVENATO, I. Administração: teoria, processo e prática. 3. ed. São Paulo: Makron Books, 2000.

CORTÉS ALONSO, V. Nuestro modelo de análisis documental. Boletim Anabad, v. 36 n. 3., p. 419-434, 1986.

DURANTI, L. Diplomática: usos nuevos para una antigua ciencia. Córdoba, 1995.

FAYOL, H. Administração industrial e geral. 8. ed. São Paulo: Atlas, 1970.

HOUAISS, A. Dicionário Houaiss da língua portuguesa. (Versão digital). Disponível em: <http://houaiss.uol. com.br/>. Acesso em: 1. dez. 2013.

LACOMBE, F. J.M. Dicionário de negócios. São Paulo: Saraiva, 2009.

LODI, J. B. História da administração. São Paulo: Atlas, 1981.

MAXIMIANO, A. C. A. Introdução à Administração. São Paulo: Atlas, 2004.

MILANI, M. S. Da escrituração no novo Código Civil. Comentários aos arts. 1179 a 1195 do código civil aprovado pela Lei n. 10.406, de 10.1.2002. São Paulo: Editora Juarez de Oliveira, 2004. 
MOREIRA, J. C. T.; PASQUALE, P. P.; DUBNER, A. G. Dicionário de termos de marketing. 4. ed. São Paulo: Atlas, 2008.

MOTTA, F. C. P. Teoria das Organizações: evolução e crítica. São Paulo: Pioneira, 1986.

PAZIN VITORIANO, M. C. C. Produção documental do legislativo no Império - gênese e tipologia: o caso da Assembleia Legislativa Provincial de São Paulo (1835-1889). 174 f. Dissertação (Mestrado em História Social). Faculdade de Filosofia, Letras e Ciências Humanas, Universidade de São Paulo, 2005.

PAZIN VITORIANO, M. C. C. Obrigação, controle e memória: aspectos legais, técnicos e culturais da produção documental de organizações privadas. São Paulo: FFLCH/USP, 2012.

RABAÇA, C. A.; BARBOSA, G. G. Dicionário de comunicação. São Paulo: Ática, 1995.

SOUZA, C. A. de; SACCOL, A. Z. (Org.) Sistemas ERP no Brasil. São Paulo: Atlas, 2003.

TAMAYO, A. Análisis diplomática de documentos. In: TAMAYO, A. Archivistica, diplomática \& sigilografia. Madrid: Cátedra, 1996. p. 55-114.

TAYLOR, F. Princípios da administração científica. São Paulo, Atlas, 1966
The influence of the legal requirements and management theory in the structure of types of documents in organizations

\section{Abstract}

Introduction: It presents a discussion on the creation and maintenance of documents 'models and formulas over the last century in private organizations, under the limitations of the legal requirement framework and the Administration Theory. Method: Desk research and analysis of three types of documents used in organizations: general ledger, payroll and folder/corporate brochure. Results: There are issues related to the regulation of documentary activities regarded to the influence of the administrative control in the analysis and document retention, as well as the changes that occurs in the most common document types that exist in a private organization. Conclusions: The structures present in the records are influenced by legal requirements to the extent that they not only require the establishment of formulas for arrange the information, but give live to other types of documents outputs. Besides, methods and techniques recommended by Management Theory influence the maintenance of traditional document types, as well as for creating new formulas.

\section{Keywords}

Archival documents. Document management. Business archives. Diplomatic. Archival legislation.

Recebido em 3 de novembro de 2013 Aceito em $1^{\circ}$ de dezembro de 2013

Sobre a autora:

\section{Marcia Cristina de Carvalho Pazin Vitoriano}

Graduação em História - USP, Especialização em Organização de Arquivos, Mestrado em História Social - USP, Doutorado em História Social - USP.

marciapazin@uol.com.br

Como citar este artigo:

PAZIN VITORIANO, M. C. de C. Influência das exigências legais e da Teoria da Administração na estrutura de tipos documentais em organizações. AtoZ: novas práticas em informação e conhecimento, Curitiba, v. 2, n. 2, p. 126-135, jul./dez. 2013. Disponivel em: <http://www.atoz.ufpr.br>. Acesso em: 